\title{
Challenges and Opportunities of Covid-19 in Agricultural Economy: The Case of Ethiopia
}

\author{
Degineh Lagiso \\ Werabe University, Department of Agricultural Economics, Werabe, Ethiopia
}

\begin{abstract}
The novel coronavirus is originated from the Wuhan state, Hubei province of China and exported to almost all countries of the world in the short period of time. Above all, it is common agenda for all individuals in the world by enforcing countries to lockdown borders, close education sectors, give commandments for civil servants to work in home, discouraging social interaction and informing about implementation of messages flowed by doctors, government and religious leaders to contain the pandemic to go forward for economic growth increase time. The objective of this review was to assess challenges and opportunities of Covid-19 in agricultural economy of Ethiopia using the methods of desk review. There are some challenges and opportunities discussed in this paper such as aggravation of food security, slowdown of service sectors, input delay, decline in foreign currency and unemployment are challenges whereas import substitution, innovation and modernization of agriculture are available opportunities for the country due to the pandemic. Even though challenges harming the hub sector of economy in the country, it opens avenues to build resilient agriculture sector that are less sensitive to shocks. To ensure this, Government has to consider multi- benefit based green economy, implement fiscal policy on tax cut and increasing government spending to stimulate agricultural production and safety net program and empowering health sectors needs due attention to the successfulness of agriculture and other sectors through collaborative hand of all stakeholders.
\end{abstract}

Keywords: Challenges, Coronavirus, Ethiopia, Opportunities, Resilience.

DOI: $10.7176 / \mathrm{JAAS} / 65-03$

Publication date:June $30^{\text {th }} 2020$

\section{Introduction}

The novel coronavirus (COVID-19) is a respiratory illness caused by a virus that was first identified at the end of 2019. As of early April 2020, WHO was reporting a continued steep rise in the number of cases and deaths worldwide, with the pandemic spreading to at least 240 countries and territories (FAO, 2020). It is originated from Wuhan town, Hubei province of China on 31 December 2019 (Guo et al., 2020). Due to absence of vaccine for the pandemic immediately after emergence, non-pharmacial measures such as isolation, mandatory quarantine, physical distancing and community containment are rapidly implemented in China and Korea (Cohen and Kupferschmidt, 2020). These actions have been shown to successfully slowdown the transmission and have led to containment of the virus (Maier and Brockmann, 2020). It is imported to by Japanese citizen who come from Burkinifaso to Ethiopia in March 12/2020. Up to now, June 8/20, Infected individuals in Ethiopia from 147,735 testing is 2,156 (of which 361 recovered, 27 died and 2 went to the country) (MOH, 2020). The virus is transmitted through sneezing, coughing, hugging, handshaking, touching, virus infected surfaces and others. It has potential to disrupt food supply chain in between rural urban areas of the country. To contain the virus, Ethiopia has adopted various measures such as physical distancing, washing hands using soap, stay at home, follow the advices of healthcare providers in line with the World Health Organization (Kaleab, 2020).

In addition, education institutions and entertainment houses were closed; increasing number of market and transportation center that enable them to keep physical distance are facilitated, performing meetings (religious And non-religious) more than four individuals were prohibited; obligatory quarantine for those who come from abroad and suspected individuals is functioning; number of passenger decreased by $50 \%$ in cars, $66.7 \%$ in bajaj and not allowed for motorbike except driver; increment in testing centers and enhancement of testing rate is going well and most civil servants are allowed to stay at home by functioning work to minimize vulnerability for the catastrophe. Moreover, government performed the establishment of pandemic prevention and control committee from federal to kebeles level, facilitating sanitation facilities, creating awareness using mass media and other means of communication and allows religious programs broadcasting on mass media for more than a month for the containment of the virus (Bacha, 2020).

The pandemic is already directly affecting food systems through impacts on food supply and demand, and indirectly through decreases in purchasing power, the capacity to produce and distribute food, and the intensification of care tasks, all of which will have differentiated impacts and will more strongly affect the poor and vulnerable (FAO, 2020). Most individuals in the rural parts of Ethiopia engaged in informal sector which helping them on their livelihoods. Due to the available catastrophe that enforce people to stay at home have given less or no chance for the individuals engaged in temporary works of agriculture. In the case of Ethiopia, most of the agriculture enterprises are labor intensive which absorb a lot of labor force to contributes a lot for the economy 
priori Covid-19 pandemic happened. Because of this pandemic, the National Planning Commission (NPC) of Ethiopia is forecasting the Ethiopian economy to be slowing down by $2.8 \%$ to $3.8 \%$. Generally, the overall result of the COVID-induced economic depression and job cuts among the investment projects may exacerbate extreme poverty and food insecurity (Mesay, 2020). Next to the pandemic fighting, it is important to focus on consolidating agricultural economy to adequately feed population of country. According Torero (2020), without food, there can be no exit from the pandemic indicated food help humanitarian in crossing the difficult catastrophe of this day which threats of all individuals worldwide. African Development Bank reported that, before the importation of Covid-19, Africa were facing silent pandemic such as malnutrition, hunger and starvation that kill hundreds of thousands of Africans year on year (ADB, 2020). Based on the stated problems, the objective of the review was to assess the challenges and opportunities of Covid-19 on Agricultural economy of Ethiopia that leads to generate genuine strategies which helps to ease the problems harm and exploit opportunities of the agriculture economy of the country.

\section{Methods}

The review was conducted on Ethiopia level to identify backbone sector that stands almost all individuals of the country by food supply such as crop, fruits, vegetables and livestock and its products. Primary data was from opinion of expert to judge available circumstances on challenges and opportunities of Covid-19 on Agricultural Economy of Ethiopia and secondary data was collected from published sources such as International Monetary Fund, Office for the Coordinated of Humanitarian Affairs, International Centre, United Economic Commission for Africa, journals, reviews and reports. No more literature that focuses on the area challenges and opportunities of the pandemic on agriculture economy of the country directly. Even if less written work available, expert focused on aggravation of food insecurity, input delay, slowdown of service sectors, decline in foreign earning and unemployment as challenges of pandemic while import substitution, innovation and modernizing agriculture as opportunities of pandemic on agriculture economy of Ethiopia.

\section{Discussion}

\section{Challenges of Covid-19 Pandemic on Agriculture Economy}

There are challenges such as aggravation of food insecurity, input delay, slowdown of service sectors, decline of foreign earning and unemployment.

\section{Aggravation of food insecurity}

Most of the individuals in the country rely on working to feed family on daily or weekly basis. This indicates that the base of the economy is very fragile like glass. Before occurrence of covid-19 an estimated 8 million people require food assistance in Ethiopia. This figure includes internally displaced persons (IDPs), who have had to leave their homes due to unrest or natural shocks (OCHA, 2020). In addition to this, About 8.5 million people are thus expected to be in Crisis (Forsido et al., 2020). Based on this data, 15\% (16.5 million) people need support of food to survive in the country. Not only this, many refugees may come from other countries that need food to survive lives. This situation aggravates food insecurity among people that lead them to frustrate if other interventions will not be taken. Similar to many countries and economic blocks such as China, EU and USA, Ethiopia may experience slower economic growth owing to the pandemic. This may worsen the already precarious food security situation of the country (Mesay, 2020). Along with COVID-19, food security in East Africa (i.e Ethiopia) is experiencing multiple threats, including the impact of desert locust, floods and insecurity (FAO, 2020). In addition, conflict among peoples gave an opportunity for displacement which was exacerbated food insecurity in the countries (GRFC, 2020). According to Yigzaw and Abitew (2019), about 1,431,682 people were internally displaced in Ethiopia as a result of conflict and violence or political instability in 2019 . This showed that considerable number of people expects the hand of the government to stay with life until they are capable to secure enabling circumstance. This difficult situation needs collaborated hands of governmental and non-governmental stakeholders to bridge up food insecure persons for bright future and contains the available global catastrophe from the country in short time using maximum effort.

\section{Input delay}

Ethiopia has landlocked economy which induce disadvantage in importing necessary factors of production for agriculture production such as inorganic fertilizers, pesticide and others. To enter these inputs from other countries, island economy of Djibouti plays almost entire role until nowadays. To take inputs moved from other countries on the behalf of Djibouti, Ethiopia facing challenges due movement restriction for current pandemic prevention. According to Forsido et al. (2020), movement restriction due to covid-19, adversely affects agricultural inputs distribution that determine food supply of near future. Shortage of agricultural inputs such as seed, fertilizers, pesticides and other chemicals as well as movement restriction may adversely affect the sector that make dream for required supply of agricultural products in the next months(Degye et al., 2020). As of mid-May, area planted 
for belg crops was below average, in part due to the delays in agriculture input distribution associated with COVID19 restrictions and the slow start of season (FEWSN, 2020). This aggravating the production shocks at alarming rate that encourage the increase in price of products for consumers. As the economy has further declined due to impacts of COVID-19, staple food prices are increasing at rates higher than what is seasonally normal for this time of year. In April, maize prices in Hossana market were 20 and 53 percent, and sorghum prices in Dessie market were 33 and 105 percent higher than the same time last year and the five-year average, respectively (FEWSN, 2020). In livestock product, the price of meat spikes due to access problems for feed and veterinary drugs by movement restriction (MC, 2020)

\section{Slowdown of service sectors}

Service sectors such as hotels, restaurants, resorts and lodge facing bankruptcy by customer loss that aroused from state of emergency which given the command for society to stay at home. This lowers the demands of agricultural products produced by enterprises. This may adversely affect perishable products such as fruits, vegetables, dairy, meat and fisheries than staple crops such as teff, maize and wheat which are less perishable and its demand is relatively inelastic. According to Seneshaw et al. (2020), the patterns of certain vegetable consumption is reduced at household for the reason of spreading of corona virus and cafes and restaurants experiencing slowdown in their business due to loss of customer by current pandemic threat that decline the demand of vegetables. This situation discourages the enterprise that provide agricultural product for preparation of various kinds of food items in aforementioned places. Due to movement restrictions, border lockdown and fear of people, the tourism is plummeting instantly which highly affect hotels, café, restaurant, resorts and similar enterprises that leading their businesses to shut down, even some of them are out of the system (DRC, 2020).

\section{Decline in foreign earning}

The current virus slowed global trade by reducing international travels and disrupting global value chains (WBG, 2020). Higher share of export from Ethiopia to the other countries is from agricultural production. Kenya, Ethiopia and Uganda are important producers of coffee, tea and cocoa, which provide an income to almost 5 million small growers. A downwards trend in demand has already decreased prices by 7 percent compared to December 2019 (DRC, 2020). According to Alemayehu (2020), export of various agricultural products such as coffee, oil seeds and pulses are expected to decline in the next two quarters of year by 11,15 and $13 \%$. The local currency of Ethiopia was devalued by about $2 \%$ against the US\$ in March. Before this, it was falling by approximately $0.5 \%$ every month following a 5.6\% fall against the US\$ in November 2019 (Ada et al., 2020). Decrement in value of currency leads to lower purchasing power parity of the country. It is simple fact that, the currency of Ethiopia (birr) is devaluating relative to United States dollar due to problem of export of goods to other countries are less to goods that are entered into the country from abroad measured in currency. The study done by Gutu (2020), Ethiopia has experience a continuous trade balance deficit, amounting to $12.5 \%$ of GDP in 2018/19 primarily reflecting a low level of exports from a mostly undiversified basket of commodities (USD 2.67 billion in 2018/19) and a high level of dependence on imported intermediate inputs, capital goods, fuel and food (wheat). Deficit in trade have great impact on foreign exchange rate in Ethiopia which currently facing devaluation of value of currency relative Unites States dollar that lead to decline the purchasing power of birr. The export sector in the country is highly correlated with agricultural products such as coffee, sesame, horticulture products, oil seeds, hide and skins to the other countries. This sector has not significant contribution on currency revaluation because more unprocessed agriculture product is exported to import less industrial output. It is fact that, the extent of export is decreasing as compared to priori pandemic because Ethiopia has extreme number of poor individuals which make them going to the bed with empty stomach as India, Nigeria, Democratic Republic of Congo and Bangladesh (Ruwan et al., 2020). To recover export of sector, National Bank of Ethiopia shared the burden imposed in the horticulture sector by removing minimum price set by the for flower exports (Brook, 2020). In addition, IMF approved 411 United States dollars to meet the urgent balance of payment needs stemming from covid-19 pandemic (IMF, 2020). Just like this, additional stimulus package is necessary for other exporting organization if financial reserve is available in the country financial institution to adjust balance of payment up to the normal level.

\section{Unemployment}

Covid-19 pandemic is discouraging foreign direct or domestic investment in the area of agriculture. This difficult condition imposes negative impact on the people who are engaged in various enterprises of aforementioned sector to sustain their life from day to day. In addition to the tensions of the pandemic, employer forcing them to exit from the jobs that make the life of employee under questions. Most of the employees are engaged in informal agricultural work which requires frequent social interactions and cannot be performed remotely. Consequently, a large number of low-skilled workers have losing their employment, raising concerns over people having to sell productive assets to meet their basic needs which would compromise economic recovery (DRC, 2020). The available outbreak will enforce to exit from already or will be engaged individuals in informal and formal works 
which lead to aggravate the level of unemployment in the country (Brook, 2020). From the one enterprise of agriculture, reduced trade leads to a reduction in employment in coffee-related business such as processing, transportation, and trading, and workers in that business often relying on daily wages will not be able to make a proper living (Seneshaw et al., 2020). In Ethiopia the horticulture sector employs nearly 200,000 people and includes 26 investment projects in the export of flower, fruits, vegetables, and herbs. The sector is being severely hit by COVID-19, leading to losses in export revenues and layoffs. In March 2020, the Ethiopian horticulture industry reportedly lost $\$ 11$ million potentially resulting in the layoff of 150,000 people. The crisis has also affected Ethiopian's banks' loan portfolio, especially those that provide finance to the sector. Zemen Bank has half-billion Birr (approximately US\$15 million) outstanding loans, advanced to companies operating in the horticulture sector (UNECA, 2020).

\section{Opportunities of Covid-19 Pandemic on Agriculture Economy Import Substitution}

Most of the goods consumed in the country is importing from the other countries including agriculture goods such as Wheat, Beer Barley, Dairy products and others. Most exporter countries may not willing to provide the product if the situation exacerbated in the future. Government of Ethiopia has taking important interventions by giving tractors, facilitating water pumps, giving direction for bare land need to be ploughed and facilitating various factors of production for the production. These enable the country to cope up from the shocks of desert locust infestation, import and existing pandemic. In addition to basic agricultural inputs, government of Ethiopia are focusing on school places, fenced places by investors and the place which were not ploughed before today is identified for production various crops to fill the gap experienced before aroused from import.

\section{Innovation}

In Ethiopia, almost all farmers are depending on rain for producing various crops. In this condition, it is difficult to balance the demand of ever increasing population relative supply side by producing once a year. Challenge by itself gives an opportunity to create new ideas to make sector of economy resilient. The pandemic is an opportunity to hit the reset button, with scientists and social scientists playing an important part. And innovation is happening: China is investing in drones, unpiloted vehicles and other agriculture technologies to reduce human contact. In Africa, mobile phones are improving access to markets, prices and weather data, as well as facilitating money transfers (Torero, 2020). And also the government of Ethiopia has mainstreaming the innovation by injecting on modern inputs such as irrigation pumps and tractors to fill the gap that have been experienced before this year. This may make severe food insecurity as a history by highly increasing the level of productivity of inputs as well as outputs in near future. Even the businesses face the threat of bankruptcy or shut down, some business shown that a little innovation and entrepreneurship can go a long way toward building resilience (ITC, 2020).

\section{Modernizing Agriculture Sector}

After Covid-19 happened in the country, government of Ethiopia has given due attention by accelerating irrigation projects to make people more resilient, facilitating water pumps and tractors to ease efforts need to be exerted to produce various agricultural commodities to compensate production and products shocks due desert locust infestation and import ban. To support modernization of agriculture sector In the Oromia region of Ethiopia, the agricultural bureau is facilitating access to agricultural inputs and providing loans for tractors for large farmers in coordination with its efforts to use model farmers that are irrigating to increase production (MC, 2020).

\section{Conclusion}

At the beginning of this year, unexpected pandemic which is Covid-19 come to stay the world people in dark situations. Ethiopia is one of the countries in the world experiencing the available difficult condition of the pandemic. The objective of the review was to assess the challenges and opportunities of Covid-19 on agricultural economy of Ethiopia by desk review approach. This review shows that even if it comes up with various challenges that hinder the performance agriculture sector, it has opportunities to make the sector less sensitive to any shocks.

\section{Recommendations}

Based on the conclusion, the following recommendation were forwarded

Firstly, government has to apply vertical agriculture using necessary inputs for crop production and strengthen the distribution of irrigation pumps, accelerating started irrigation projects and facilitating farm tractors for farmers; Secondly, government should encourage green economy that considers multipurpose advantages such as income from fruits, tourism, biodiversity and serves as input for beekeeping that ensure resilience for farmers at the time of shocks happened;

Thirdly, implementing fiscal policy that consider current situation by reducing tax levied on agriculture enterprises and encourage government spending to strength agricultural production through timely input provision with 
support and safety net program through mobilizing food banks in various centers are essential to support food insecure people of the country;

Fourthly, Side by side of encouraging agricultural production, optimum level measurements need to be taken by the government to contain available pandemic to interact with other countries relatively in near period of control that ease difficulty of all sectors.

Lastly, government needs to focus on agricultural input production such as manure, inorganic fertilizers, pesticide using available resources to substitute import which keep away currency will be paid for inputs.

\section{Author details}

Department of Agricultural Economics, Werabe University, Werabe, Ethiopia.

\section{REFERENCES}

Ada Zakrzewska, Eleanor Keeble, Jacklyn Sullivan, Moges Beyene, Supraja Vadlamani 2020, Economic impacts of and policy responses to the coronavirus pandemic: early evidence from Ethiopia

African Development Bank (ADB) 2020, Building Resilience in Food Systems and Agricultural Value Chains: Agricultural Policy Responses to COVID-19 in Africa, a Brainstorming E-Policy Seminar

Alewmayehu Geda 2020, The Macroeconomic and Social Impact of COVID-19 in Ethiopia and Suggested Direction for Policy Response

Bacha Kebede 2020, Covid-19 Pandemic and Ethiopian Public Administration: Responses and Challenges.

Brook Kebede 2020, The Economic and Legislative Responses to Mitigate the impact of Covid-19 on Private Employees In Ethiopia

Cohen, J., K. Kupferschmidt 2020, “Countries test tactics in 'war 'against COVID-19.” Science, 367, 6484: $1287-$ 1288. EPHI (Ethiopian Public Health Institute). 2020. Rapid Evidence Synthesis on COVID-19 Pandemic to Inform the Ethiopian Ministry of Health $(\mathrm{MoH})$. Addis Ababa: EPHI.

Danish Refugee Council (DRC) 2020, The ripple effect of COVID-19 on economic activities, livelihoods and food security in East Africa and the Great Lakes.

Degye Goshu, Tadele Ferede, Getachew Diriba, Mengistu Ketema 2020, Economic and Welfare Effects of COVID-19 and Responses in Ethiopia: Ethiopian Economic Policy Research Institute (EEPRI), Initial insights. Policy Working Paper 02/2020

Famine Early Warning Systems Network (FEWSN) 2020, COVID-19 related restrictions alongside multiple food security drivers limit food access

Forsido, SF., Mitiku, F., Lemessa, F., Tolemariam, T., Belew, D., Berecha, G., Garedew, W., Bekele, Y., Geda, F., Eneyew, A. 2020, COVID-19 Probable Impacts on Ethiopian Agriculture and Potential Mitigation and Adaptation Measures: No Food-No Health-No Life. Jimma, Ethiopia: Jimma University, 2020.

Global Report on Food Crises (GRFC) 2020, Food Security Information Network

Guo, Z. D. et al. 2020, Aerosol and Surface Distribution of Severe Acute Respiratory Syndrome Coronavirus 2 in Hospital Wards, Wuhan, China, 2020, Volume 26, Number 7, Centers for Disease Control and Prevention (CDC).

Gutu Tesso. 2020, The Economics of COVID-19: Economic Growth, Unemployment and the Challenge to Progress out of Poverty in Ethiopia

International Monetary Fund (IMF) 2020, The Federal Democratic Republic of Ethiopia. IMF Country Report No. $20 / 150$

International Trade Centre (ITC) 2020, Unsung Heroes: How Small Farmers Cope with COVID-19. ITC, Geneva. Kaleab Baye 2020, COVID-19 prevention measures in Ethiopia: Current realities and prospects

Maier, BF., D Brockmann 2020, "Effective containment explains sub-exponential growth in recent confirmed COVID-19 cases in China", Science, DOI: 10.1126/science.abb4557

Mercy Corps (MC) 2020, Covid-19 Rapid Market Impact Report

Mesay Mulugeta 2020, The Impact of COVID-19 Pandemic on Food Security in Ethiopia.

Minstry of Health (MOH) 2020, www.ephi.gov.et, ephieoc@gmail.com,www. facebook.com/ephipage

OCHA 2020, Humanitarian Needs Overview Snapshot, UN Office for the Coordination of Humanitarian Affairs (OCHA)

Ruwan Ranasinghe, Chandi Karunarathna, Jayathree Pradeepamali 2020, After Corona (Covid19) Impacts on Global Poverty and Recovery of Tourism Based Service Economies: an Appraisal. Department of Tourism Studies Uva Wellassa University of Sri Lanka

Seneshaw Tamru, Ermias Engida, Bart Minten 2020, Impacts of the COVID-19 crisis on coffee value chains in Ethiopia

Torero, M. 2020, Without food, there can be no exit from the pandemic, Nature, Vol 580, 30 April 2020, 588-59. URL: https://www.nature.com/articles/d41586-020-01181-3

United Nation Economic Commission for Africa (UNECA) 2020, Protecting Lives and Economies, Covid-19 in 
Africa.

Yigzaw Gedifew, Abitew Endalsasa 2019, Causes and Impacts of Internal Displacement in Ethiopia, African Journal of Social Work, 9, 2: 32-41 